\title{
Tiotropium Bromide
}

National Cancer Institute

\section{Source}

National Cancer Institute. Tiotropium Bromide. NCI Thesaurus. Code C84608.

The bromide salt form of tiotropium, a quaternary ammonium derivative of atropine and a muscarinic receptor antagonist, with bronchodilating activity. Although it does not display selectivity for specific muscarinic receptors, on topical application, tiotropium bromide acts mainly on M3 muscarinic receptors located on smooth muscle cells and submucosal glands, preventing smooth muscle contraction and mucus secretion, thus producing a bronchodilatory effect. 